\title{
Publisher Correction: Phosphoric acid-catalyzed atroposelective construction of axially chiral arylpyrroles
}

\author{
Lei Zhang ${ }^{1}$, Shao-Hua Xiang (10 1,2, Jun (Joelle) Wang (1) ${ }^{1}$, Jian Xiao ${ }^{3}$, Jun-Qi Wang ${ }^{4} \&$ Bin Tan (1) ${ }^{1}$
}

Correction to: Nature Communications https://doi.org/10.1038/s41467-019-08447-z, published online 4 February 2019.

The original PDF version of this Article contained an error in Table 3, in which all chemical structures were omitted and only the numerical data was shown. This has been corrected in the PDF version of the Article. The HTML version was correct from the time of publication.

Published online: 26 April 2019

\begin{abstract}
(c) (i) Open Access This article is licensed under a Creative Commons Attribution 4.0 International License, which permits use, sharing, adaptation, distribution and reproduction in any medium or format, as long as you give appropriate credit to the original author(s) and the source, provide a link to the Creative Commons license, and indicate if changes were made. The images or other third party material in this article are included in the article's Creative Commons license, unless indicated otherwise in a credit line to the material. If material is not included in the article's Creative Commons license and your intended use is not permitted by statutory regulation or exceeds the permitted use, you will need to obtain permission directly from the copyright holder. To view a copy of this license, visit http://creativecommons.org/licenses/by/4.0/.
\end{abstract}

(C) The Author(s) 2019

\footnotetext{
${ }^{1}$ Department of Chemistry and Shenzhen Grubbs Institute, Southern University of Science and Technology, Shenzhen 518055, China. ${ }^{2}$ Academy for Advanced Interdisciplinary Studies, Southern University of Science and Technology, Shenzhen 518055, China. ${ }^{3}$ College of Chemistry and Pharmaceutical Sciences, Qingdao Agricultural University, Qingdao 266109, China. ${ }^{4}$ Department of Biology, Southern University of Science and Technology, Shenzhen 518055, China. Correspondence and requests for materials should be addressed to J.W. (email: wang.j@sustc.edu.cn) or to

B.T. (email: tanb@sustc.edu.cn)
} 